\title{
Transenamel and Transdentinal Penetration of Hydrogen Peroxide Applied to Cracked or Microabrasioned Enamel
}

\author{
ALF Briso • APB Lima • RS Gonçalves \\ MO Gallinari $\bullet \mathrm{PH}$ dos Santos
}

\begin{abstract}
Clinical Relevance
Microabrasion and the presence of cracks in enamel make this substrate more susceptible to penetration of hydrogen peroxide during in-office whitening.
\end{abstract}

\section{SUMMARY}

The present study evaluated transenamel and transdentinal penetration of hydrogen perox-

*André L F Briso, DDS, MSc, PhD, associate professor, Restorative Dentistry, Araçatuba School of Dentistry, São Paulo State University - UNESP, Araçatuba, São Paulo, Brazil

Ana Paula Batista Lima, undergraduate student, Restorative Dentistry, Araçatuba School of Dentistry, São Paulo State University - UNESP, Araçatuba, São Paulo, Brazil

Rafael Simøes Gonçalves, DDS, MSc student, Restorative Dentistry, Araçatuba School of Dentistry, São Paulo State University - UNESP, Araçatuba, São Paulo, Brazil

Marjorie Oliveira Gallinari, undergraduate student, Restorative Dentistry, Araçatuba School of Dentistry, São Paulo State University - UNESP, Araçatuba, São Paulo, Brazil

Paulo Henrique dos Santos, DDS, MSc, PhD, associate professor, Dental Materials and Prosthodontics, Araçatuba School of Dentistry, São Paulo State University - UNESP, Araçatuba, São Paulo, Brazil

*Corresponding author: Restorative Dentistry, Araçatuba Dental School, São Paulo State University - UNESP, R José Bonifácio, 1193, Araçatuba, São Paulo 16015-050, Brazil; e-mail: alfbriso@foa.unesp.br

DOI: $10.2341 / 13-014-\mathrm{L}$ ide during tooth whitening recognized in altered enamel by the presence of cracks or microabrasion. We used 72 experimental units $(n=20)$ obtained from bovine incisors: GI-sound enamel; GII-teeth showing visible enamel cracks (4 mm to $5.7 \mathrm{~mm}$ in length); and GIIImicroabrasioned enamel. The 12 remaining specimens were used to analyze the enamel surface morphology using scanning electron microscopy. The specimens were cylindrical and $5.7 \mathrm{~mm}$ in diameter and $3.5 \mathrm{~mm}$ thick. A product based on $35 \%$ hydrogen peroxide was used for bleaching, following the manufacturer's recommendations for use. To quantify the $\mathrm{H}_{2} \mathrm{O}_{2}$ penetration, the specimens were placed in artificial pulp chambers containing an acetate buffer solution. After bleaching, the solution was collected and adequately proportioned with leucocrystal violet, peroxidase enzyme, and deionized water. The resulting solution was evaluated using ultraviolet visible reflectance spectrophotometer equipment. The data were analyzed by analysis of variance (ANOVA) and Fisher's PLSD at a significance level of 0.05, and significant differences in the penetration 
of peroxide in different substrate conditions were observed $(p<0.0001)$. The penetration of hydrogen peroxide was more intense in cracked teeth. The group in which the enamel was microabraded showed intermediate values when compared to the control group. Microabrasion and the presence of cracks in the enamel make this substrate more susceptible to penetration of hydrogen peroxide during inoffice whitening.

\section{INTRODUCTION}

Although tooth bleaching has been considered a conservative technique ${ }^{1-3}$ associated with ease of implementation and highly efficient performance, ${ }^{4}$ there are concerns about the biologic safety of the procedure, referring to the indiscriminate use of highly concentrated peroxide products. Studies have shown that the diffusion of hydrogen peroxide through dental tissues may cause pulpal damage $\mathrm{e}^{5-7}$ and increased postoperative sensitivity. ${ }^{8,9}$

Even though the success of a bleaching treatment is directly related to the diffusion capacity of peroxides through enamel and dentin, it is believed that the more intense the penetration, the higher the risk of occurrence of side effects. Thus, bleaching is contraindicated in clinical conditions in which the tooth presents exposed dentin or other enamel tissue changes that presumably increase its permeability.

Cracks in the enamel are common but often are ignored or not noticed. These changes appear as fissures within the structure of the enamel and extend preferably along the cervico-incisal axis and may even reach the dentino-pulpal complex, which can also cause fractures in the tooth structure. ${ }^{10-14}$ Thus, it seems possible that the presence of these changes may affect the intensity of hydrogen peroxide diffusion toward the pulp chamber.

Another common clinical condition refers to chromatic or textural changes on the enamel surface layers. In these cases, clinicians use a microabrasive treatment, which is an excellent choice for removing these changes by providing improved esthetics with a minimally invasive treatment. ${ }^{15-19}$ Despite reports that the wear of microabrasion is small, ${ }^{16,18,19}$ it is important to consider that the removal of the aprismatic layer and the conditioning provided by acids in these products can potentially alter the permeability of dental tissues.

Even though these clinical findings are relatively common, the literature shows no studies that quantify or compare the penetration levels of hydro- gen peroxide when the bleach is applied in these conditions. Therefore, considering that the presence of cracks and enamel microabrasion represent tissue changes with potential influence on its permeability, studies are needed to assess the real impact of these changes on the intensity of hydrogen peroxide diffusion toward the pulp chamber.

\section{MATERIALS AND METHODS}

\section{Experimental Design}

The factors studied were the presence of cracks in enamel and enamel microabrasion. The response variable was the transenamel and transdentinal penetration of hydrogen peroxide, and the three basic principles of experimentation (repetition, randomization, and blocking) were observed. The sample had 72 teeth, 60 intended for the penetration study $(n=20)$ and 12 for photomicrographs of the enamel surfaces $(n=2)$.

\section{Collection and Standardization of Specimens}

Seventy-two experimental units were obtained from bovine incisors aged between 24 and 30 months. Those with stains on the enamel and/or excessive wear on the incisal were excluded.

The selected teeth were cleaned mechanically with periodontal curettes and received prophylaxis with pumice and water. Subsequently, they were fixed on a device attached to a drill platform bench (FGC-16 model, Ferrari, São Paulo, SP, Brazil). Cylinders were obtained from the middle third of the buccal surface $(5.7 \mathrm{~mm}$ in diameter) with the aid of a diamond tip to cut glass (Diamond tip, $08 \mathrm{~mm}$ in diameter, Dinser Diamond Tools Ltda, Sacomã, SP, Brazil) and under constant irrigation.

The dentin surface was regularized through manual rotation movements using 600 grit aluminum oxide sandpaper (T469-SF-Noton, Saint-Gobam Abrasives Ltda, Jundiai, SP, Brazil)—until the specimens presented a thickness of $3.5 \mathrm{~mm}$ (approximately 1.3 $\mathrm{mm}$ and $2.2 \mathrm{~mm}$ of enamel and dentin, respectively), measured in a digital caliper (500 to 144 B, Mitutoyo South America Ltda, Suzano, SP, Brazil). The smear layer formed during grinding was removed by applying EDTA solution for one minute, and then the specimens were rinsed with deionized water.

\section{Division of the Groups}

The analysis of the enamel was done by stereomicroscopy (Stemi SV11, Carl Zeiss, Jena, Germany) at $45 \times$ to select sound and cracked enamel. After the selection and standardization of specimens, these 
were divided into three groups $(\mathrm{n}=20)$. The 12 remaining specimens were used to analyze the enamel surface morphology using scanning electron microscopy (SEM).

Specimens were selected with no cracks for groups I and III. In group II, there were teeth with only cracks, with a length approximately that of the specimen diameter (between 4 and $5.7 \mathrm{~mm}$ ).

The specimens of group I and II did not receive any treatment prior to bleaching. The specimens of group III received ten 15-second applications of the microabrasive Whiteness RM product (FGM Dental Products, Joinville, SC, Brazil). The product was applied with a rubber cup mounted in a 10:1 speed reduction contra angle. After the applications, the specimens were washed and dried, with each rubber cup used for only one specimen.

\section{Preparation of Artificial Pulp Chamber}

Each enamel/dentin disc was adapted individually to an artificial pulp chamber (APC), developed at the Laboratory of Experimental Pathology and Biomaterials of Araraquara School of Dentistry - UNESP. ${ }^{20}$ Each APC was formed with two compartments: in the upper portion, an opening with a $8 \mathrm{~mm}$ diameter and, in the second compartment, an opening with a $6 \mathrm{~mm}$ diameter allowed for the appropriate positioning and lateral sealing of the specimen. The lower portion contained lateral perforations for circulation of the solution and was used to quantify the peroxide penetrating the specimen (Figure 1).

The specimens were positioned in the APCs between two silicone rings (5.60 mm inner diameter; $1.78 \mathrm{~mm}$ thick; Ref. OR 008 - Rodimar Rolamentos Ltda, Araraquara, SP, Brazil) and sealed with pink wax, restricting the lateral penetration of the bleaching agent (Figure 1).

\section{Whitening Procedure}

The specimens from all three groups were submitted to three in-office bleaching sessions using $0.04 \mathrm{~mL}$ of $35 \%$ hydrogen peroxide (Whiteness HP Maxx, FGM Dental Products). The product was deposited on the enamel and reapplied twice each session, for a total exposure time of 45 minutes per whitening session. All manipulation was performed in accordance with the manufacturer's instruction.

\section{Quantification of $\mathrm{H}_{2} \mathrm{O}_{2}$ Penetration}

For quantification of the $\mathrm{H}_{2} \mathrm{O}_{2}$ that penetrated the enamel/dentin discs, the artificial pulp chambers

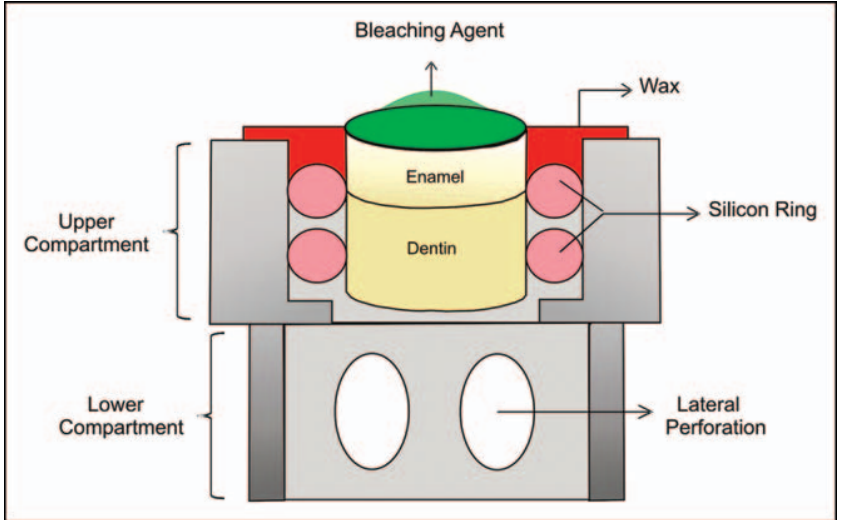

Figure 1. Enamel/dentin disc positioned in the artificial pulp chamber.

were individually placed in wells of acrylic cell culture plates. Each well was filled with $1 \mathrm{~mL}$ of acetate buffer solution and subsequently received APCs, already containing the dental fragments. Thus, the dentin surface remained in contact with the acetate solution during all bleaching procedures, and the diffused hydrogen peroxide became part of the same.

After the whitening procedure was done, $25 \mu \mathrm{L}$ of acetate buffer solution was removed and mixed with $2.750 \mu \mathrm{L}$ of distilled water, $100 \mathrm{~mL}$ of leucocrystal violet $(0.5 \mathrm{mg} / \mathrm{mL}$, Sigma Chemical Co, St Louis, MO, USA), and $50 \mu \mathrm{L}$ of peroxidase $(1 \mathrm{mg} / \mathrm{mL}$, Sigma Chemical Co) and the solution was diluted to a final volume of $3 \mathrm{~mL}$ with distilled water.

This method is based on the reaction of hydrogen peroxide with leucocrystal violet, catalyzed by the peroxidase enzyme. ${ }^{6,21-27}$ The coloring of the mixture varies in intensity according to the amount of peroxide. Thus, as the signal is proportional to the absorbance of the peroxide concentration, it is possible to assess indirectly the amount of peroxide that has penetrated the tooth surface and the solution contained in the wells.

Readings were done using ultraviolet visible reflectance spectrophotometer equipment (UV-2450, Shimadzu, Kyoto, Japan), 30 minutes after each bleaching session (Figure 2).

To obtain the calibration factor (CF) equivalent to the ratio of the concentration of the standard solution of hydrogen peroxide to its absorbance, the following equation was used:

$$
C F=\frac{[\text { Sample Solution }]}{\text { Absorbance }}
$$

The average calibration factor was used to calculate the hydrogen peroxide concentration contained in 


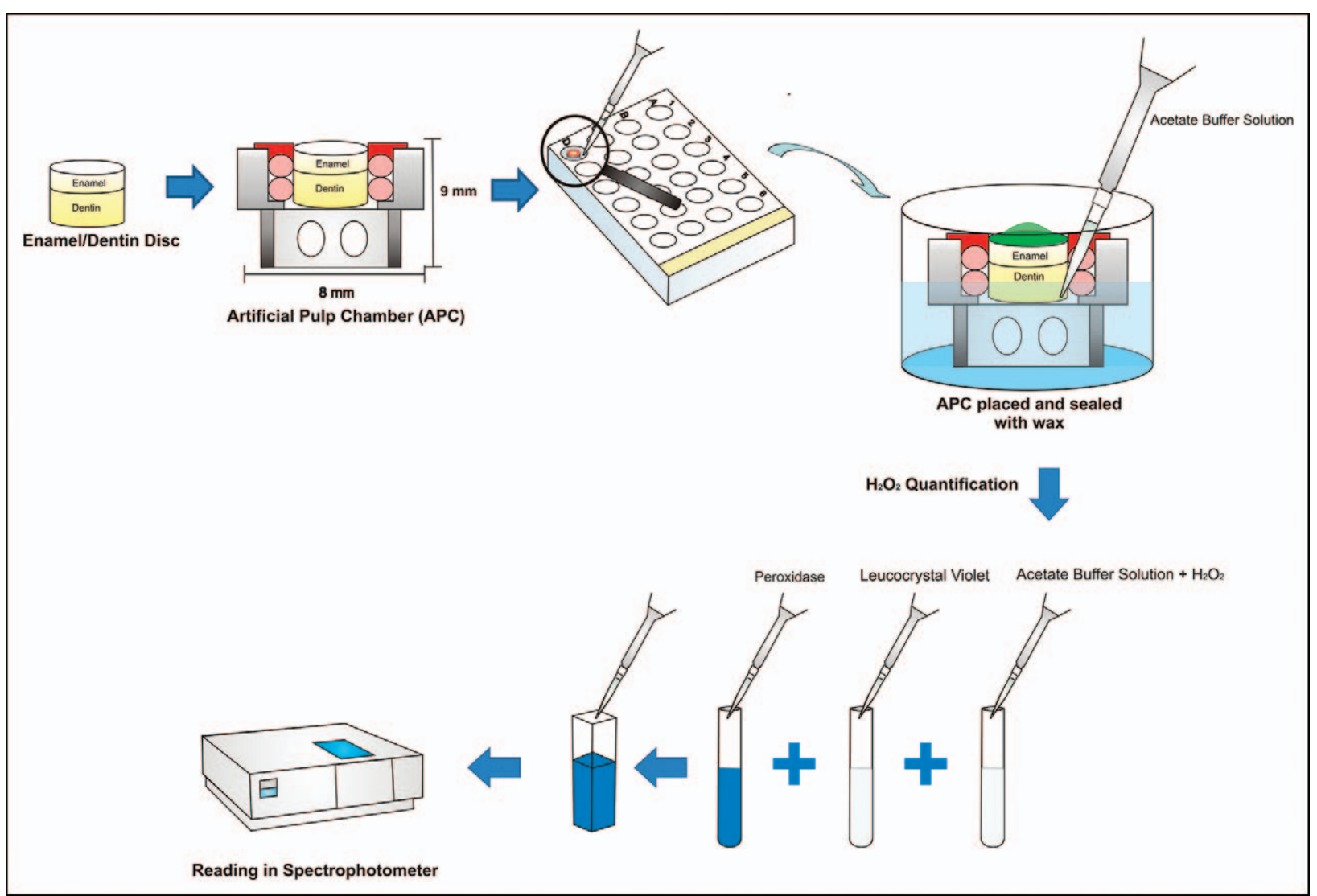

Figure 2. Scheme of the sequence of the methodology employed in the quantification of hydrogen peroxide.

each specimen. Data were tabulated and verified the normality and homogeneity of variance assumptions. Parametric tests were performed using analysis of variance (ANOVA) and Fisher's PLSD test, using the statistical program Stat View software, at a significance level of 0.05 .

For illustrative purposes and to seek more plausible explanations for the results, the enamel surface morphologies of two specimens of each group were prepared for analysis using SEM (EVO HD LS-15, Carl Zeiss, Jena, Germany). The specimens were cleaned, dried, sputter coated, and photomicrographs were taken of the dental enamel under different conditions of study, at $3000 \times$ magnification.

\section{RESULTS}

The application of ANOVA showed significant differences in transenamel and transdentinal penetration of hydrogen peroxide at different substrate conditions $(p<0.0001)$. The penetration was similar in the three bleaching sessions $(p=0.3624)$, and there was no interaction between the substrate condition and the bleaching sessions $(p=0.5320)$.
Table 1 shows that the quality of the substrate influenced the intensity of transenamel and transdentinal penetration of hydrogen peroxide, confirming higher hydrogen peroxide penetration in cracked teeth (GII). The microabraded enamel tooth (GIII) had intermediate values, and the control group (GI) always provided the greatest challenges for peroxide penetration.

\section{DISCUSSION}

Bovine teeth are convenient for laboratory study because they are easy to obtain in large quantities and have appropriate dimensions for artificial pulp chambers; bovine teeth also present uniform composition and have low variation in the experimental response. ${ }^{23,28-31}$

The methodology used in this study was proposed by Mottola and others ${ }^{21}$ and is characterized by precision and selectivity of reagents prior to exposure to hydrogen peroxide. Thus, it is important to note that the values obtained show only the concentration of hydrogen peroxide in the solution 
Table 1: $\mathrm{H}_{2} \mathrm{O}_{2}$ Average in $\mu \mathrm{g}$ (Standard Deviation) Accompanied by the Statistical Groups, Verified by Applying the Fisher's PLSD Test ${ }^{*}$

\begin{tabular}{|llcc|}
\hline & Sound & Cracked & Microabrasioned \\
\hline $1^{\text {a }}$ Session & $6.01(0.93) \mathrm{Ac}$ & $9.44(1.71) \mathrm{Aa}$ & $7.81(1.78) \mathrm{Ab}$ \\
\hline $2^{\mathrm{a}}$ Session & $6.12(1.26) \mathrm{Ac}$ & $9.81(1.81) \mathrm{Aa}$ & $8.69(1.47) \mathrm{Ab}$ \\
\hline $3^{\text {a }}$ Session & $6.65(0.72) \mathrm{Ac}$ & $9.28(1.68) \mathrm{Aa}$ & $8.06(1.12) \mathrm{Ab}$ \\
\hline${ }^{*}$ Statistical groups are denoted by letters: capital letters in the columns and lowercase letters in the rows $(p<0.05)$. The amount of $\mathrm{H}_{2} \mathrm{O}_{2}$ is contained in $3 \mathrm{~mL}$ of solution. \\
\hline
\end{tabular}

and not the other substances produced by the decomposition of the bleaching agents.

Even though vital tooth whitening is considered a conservative treatment, ${ }^{1,2}$ there are concerns regarding the use of highly concentrated products because human teeth treated with these substances exhibit high levels of sensitivity ${ }^{8,9}$ and demonstrate irreversible pulp damage. ${ }^{20,32-35}$

Even when considering enamel to be semipermeable, some clinical conditions can lead to compromised biologic safety of the bleaching procedure. The amount of peroxide that reaches the pulp-dentin complex can be altered to interfere with pulpal health. ${ }^{8,20,34}$

Results show that the presence of cracks and the enamel microabrasion procedure allowed greater penetration of hydrogen peroxide when compared to sound teeth.

In this context, the aim of the enamel microabrasion and the removal or reduction of chromatic changes or irregularities of the enamel surface may represent a health concern for the pulp-dentin complex. Once the microabrasive action changes the enamel histomorphology, the tooth becomes more permeable. ${ }^{15,17,18,19}$ In these cases, there is a need for complementing the esthetic treatment with bleaching because yellowing of the dentin tissue becomes more apparent. ${ }^{19}$ In most cases, the combination of these techniques is a treatment plan of relatively low cost and provides a great possibility to obtain optimum esthetic results. However, until now, there were no obvious possible biologic implications that bleaching can cause after microabrasion.

It is believed that rubbing the abrasive on the destructured enamel, caused by the acid $\mathrm{pH}$ of the product, alters its surface layer and perhaps the enamel permeability, making it more susceptible to the bleaching agent's penetration. Additionally, this acid-abrasive process reduces the enamel thickness, ${ }^{15,17,18,19}$ and the obstacles to peroxide penetration.
In the same way, the enamel often presents cracks which, depending on length, may be continuous with the pulp-dentin complex. ${ }^{36-38}$ This fact justifies precautions when dental products could inadvertently be applied to the adamantine substrate.

A crack is a rupture of the tissue into two or more parts and may involve different dental tissues or be restricted to a small portion of the enamel surface. ${ }^{37}$ In the present study, we selected samples showing visible cracks with an extension varying between 4 and $5.7 \mathrm{~mm}$. As during the sample preparation, there was no enamel/dentin separation; the cracks represented the presence of fissures only in the enamel structure, not across the dentin-enamel junction. But, even when taking the necessary precautions in the standardized sample, the high penetration rates observed in cracked specimens show that these pathways greatly facilitate the passage of bleaching agents that quickly reach the dentinal tubules. Perhaps this occurrence explains the frequent reports and complaints about the increase of tooth sensitivity during bleaching in patients with this clinical condition. ${ }^{10,13,39,40}$

Because they are difficult to diagnose, cracks can be neglected or overlooked by some professionals, who are often unaware of the consequences of the free passage of dental products for the pulp-dentin complex.

These results underscore the importance of maintaining intact enamel before the start of treatment. In cases using both microabrasion and whitening, tooth whitening should occur first because enamel changes that indicate microabrasion may be imperceptible after bleaching treatments. Furthermore, and most important, the presence of the sound enamel will be more effective in modulating the levels of peroxide penetration into the pulp tissue than microabraded enamel. On the other hand, careful clinical examination of cracks is important; cracks can be identified and confirmed by the naked eye or simply via macrography, microscopy, or transillumination. ${ }^{13,41}$ These structural defects should be obliterated before 

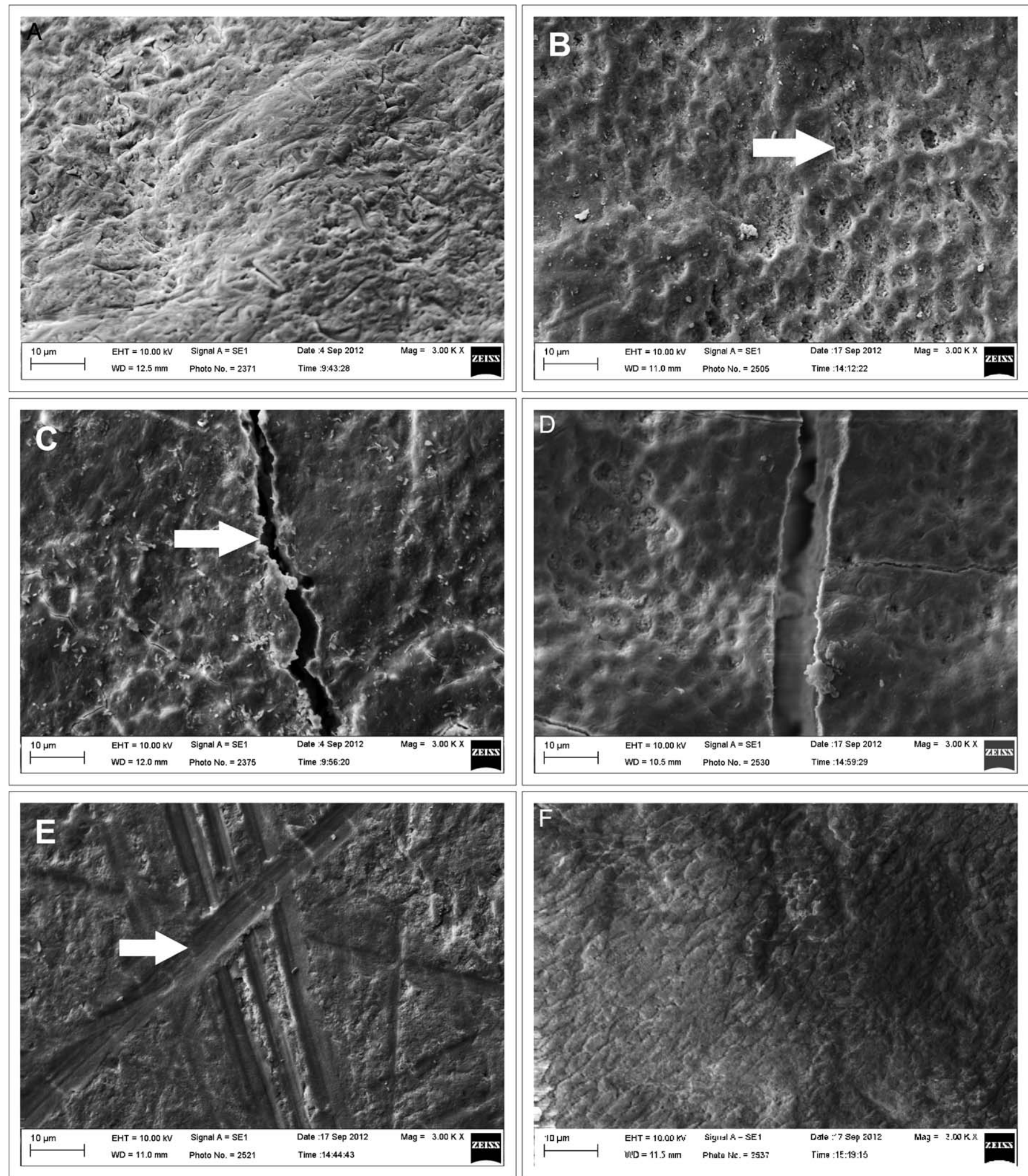

Figure 3. (A): Specimen from the control group showing the characteristic diffusion enamel channels (3000x). (B): After the bleaching treatment, note the removal of part of the aprismatic layer and partial dissolution of the prisms (arrow) (3000). (C): Specimen showing cracks in the enamel (arrow). Compared to the remaining structure, this structural defect is important in the formation of a continuous solution with the dentin pulp complex (3000 ). (D): After the bleaching procedure, besides the crack, there is a partial dissolution of the aprismatic layer and increased porosity, forming new diffusion enamel channels for peroxide (3000X). (E): Microabrasioned enamel tooth, with grooves in the surface (arrow) (3000X). (F): Enamel surface previously microabrasioned exposed to 35\% HP. Note the removal of the grooves and the view of the enamel prisms openings (3000). 
starting the bleaching treatment. For this purpose, there are clinical reports of utilizing total-etch adhesive systems, self-etch adhesives, and pit and fissure sealants. ${ }^{42,43}$

The results of in vitro studies cannot be directly extrapolated to clinical situations. The penetration of hydrogen peroxide in the bovine teeth was less when compared with that in human teeth. The thickness of the aprismatic enamel layer in bovine teeth and reduction in diameter of the tubules as they approach the pulp chamber are different from what occurs in human dentin. ${ }^{22}$ Moreover, the presence of intrapulpal pressure, cytoplasmic processes of odontoblasts, the constant demineralization/remineralization cycles, and the presence of saliva may decrease peroxide diffusion..$^{34,44-47}$ Thus, more studies evaluating these different conditions are needed to establish a secure protocol.

\section{CONCLUSIONS}

Considering these results, enamel microabrasion makes this substrate more susceptible to hydrogen peroxide penetration. In addition, teeth presenting cracks in the enamel allow greater hydrogen peroxide penetration during in-office whitening.

\section{Acknowledgements}

This investigation was supported by FAPESP \# 2011/10701-0 (The State of São Paulo Research Foundation).

\section{Conflict of Interest}

The authors have no proprietary, financial, or other personal interest of any nature or kind in any product, service, and/or company that is presented in this article.

(Accepted 8 March 2013)

\section{REFERENCES}

1. Darnell DH, \& Moore WC (1990) Vital tooth bleaching: The White and Brite technique Compendium of Continuing Education in Dentistry 11(2) 86, 88-90, 92-84.

2. Sulieman M, Addy M, Macdonald E, \& Rees JS (2005) The bleaching depth of a 35\% hydrogen peroxide based inoffice product: A study in vitro Journal of Dentistry 33(1) $33-40$.

3. Almeida LC, Riehl H, Santos PH, Sundfeld ML, \& Briso AL (2012) Clinical evaluation of the effectiveness of different bleaching therapies in vital teeth International Journal of Periodontics \& Restorative Dentistry 32(3) 303-309.

4. Spalding M, Taveira LA, \& de Assis GF (2003) Scanning electron microscopy study of dental enamel surface exposed to $35 \%$ hydrogen peroxide: Alone, with saliva, and with $10 \%$ carbamide peroxide Journal of Esthetic and Restorative Dentistry 15(3) 154-164; discussion 165.
5. Buchalla W, \& Attin T (2007) External bleaching therapy with activation by heat, light or laser-a systematic review Dental Materials 23(5) 586-596.

6. Camargo SE, Valera MC, Camargo CH, Gasparoto Mancini MN, \& Menezes MM (2007) Penetration of 38\% hydrogen peroxide into the pulp chamber in bovine and human teeth submitted to office bleach technique Journal of Endodontics 33(9) 1074-1077.

7. de Almeida LC, Costa CA, Riehl H, dos Santos PH, Sundfeld RH, \& Briso AL (2012) Occurrence of sensitivity during at-home and in-office tooth bleaching therapies with or without use of light sources Acta Odontológica Latinoamericana 25(1) 3-8.

8. Nathanson D (1997) Vital tooth bleaching: Sensitivity and pulpal considerations Journal of the American Dental Association 128(Supplement) 41S-44S.

9. Tredwin CJ, Naik S, Lewis NJ, \& Scully C (2006) Hydrogen peroxide tooth-whitening (bleaching) products: Review of adverse effects and safety issues British Dental Journal 200(7) 371-376.

10. Ritchey B, Mendenhall R, \& Orban B (1957) Pulpitis resulting from incomplete tooth fracture Oral Surgery, Oral Medicine, and Oral Pathology 10(6) 665-670.

11. Rasmussen ST, Patchin RE, Scott DB, \& Heuer AH (1976) Fracture properties of human enamel and dentin Journal of Dental Research 55(1) 154-164.

12. Hassan R, Caputo AA, \& Bunshah RF (1981) Fracture toughness of human enamel Journal of Dental Research 60(4) $820-827$.

13. Cameron CE (1976) The cracked tooth syndrome: Additional findings Journal of the American Dental Association 93(5) 971-975.

14. Abbott P, \& Leow N (2009) Predictable management of cracked teeth with reversible pulpitis Australian Dental Journal 54(4) 306-315.

15. Sundfeld RH, Croll TP, Briso AL, de Alexandre RS, \& Sundfeld Neto D (2007) Considerations about enamel microabrasion after 18 years American Journal of Dentistry 20(2) 67-72.

16. Croll TP, Segura A, \& Donly KJ (1993) Enamel microabrasion: New considerations in 1993 Practical Periodontics and Aesthetic Dentistry 5(8) 19-28; quiz 29.

17. Croll TP, \& Cavanaugh RR (1986) Enamel color modification by controlled hydrochloric acid-pumice abrasion. I. technique and examples Quintessence International 17(2) 81-87.

18. Alves J, Mondelli J, Sundfeld RH, Sundfeld MLMM, \& Alves JAD (2004) Microscopic evaluation of enamel superficial wear. Effect of the application of different microabrasive pastes. Jornal Brasileiro de Dentística \& Estetica 3 142-153.

19. Sundfeld RH, Croll TP, \& Killian CM (2002) Smile recovery: VII. Proving the efficiency and versatility of the enamel microabrasion technique. Jornal Brasileiro de Dentística \& Estetica 1(1) 77-86.

20. Trindade FZ, Ribeiro AP, Sacono NT, Oliveira CF, Lessa FC, Hebling J, \& Costa CA (2009) Trans-enamel and trans-dentinal cytotoxic effects of a $35 \% \mathrm{H} 2 \mathrm{O} 2$ bleaching 
gel on cultured odontoblast cell lines after consecutive applications International Endodontic Journal 42(6) 516524, http://dx.doi.org/10.1111/j.1365-2591.2009.01544.x.

21. Mottola HA, Simpson BE, \& Gorin G (1970) Absorptiometric determination of hydrogen peroxide in submicrogram amounts with leuco crystal violet and peroxidase as catalyst Analytical Chemistry 42(3) 410-411.

22. Camargo SE, Cardoso PE, Valera MC, de Araujo MA, \& Kojima AN (2009) Penetration of 35\% hydrogen peroxide into the pulp chamber in bovine teeth after LED or Nd:YAG laser activation European Journal of Esthetic Dentistry 4(1) 82-88.

23. Benetti AR, Valera MC, Mancini MN, Miranda CB, \& Balducci I (2004) In vitro penetration of bleaching agents into the pulp chamber International Endodontic Journal 37(2) $120-124$.

24. Gokay O, Tuncbilek M, \& Ertan R (2000) Penetration of the pulp chamber by carbamide peroxide bleaching agents on teeth restored with a composite resin Journal of Oral Rehabilitation 27(5) 428-431.

25. Cooper JS, Bokmeyer TJ, \& Bowles WH (1992) Penetration of the pulp chamber by carbamide peroxide bleaching agents Journal of Endodontics 18(7) 315-317.

26. Palo R, Bonetti-Filho I, Valera M, Camargo C, Camargo S, Moura-Netto C, \& Pameijer C (2012) Quantification of peroxide ion passage in dentin, enamel, and cementum after internal bleaching with hydrogen peroxide Operative Dentistry 37(6) 660-664.

27. Palo RM, Valera MC, Camargo SE, Camargo CH, Cardoso PE, Mancini MN, \& Pameijer CH (2010) Peroxide penetration from the pulp chamber to the external root surface after internal bleaching American Journal of Dentistry 23(3) 171-174.

28. Schmeling M, Maia HP, \& Baratieri LN (2012) Opalescence of bleached teeth Journal of Dentistry 40(Supplement 1) e35-39.

29. Kwon YH, Huo MS, Kim KH, Kim SK \& Kim YJ (2002) Effects of hydrogen peroxide on the light reflectance and morphology of bovine enamel Journal of Oral Rehabilitation 29(5) 473-477.

30. Attin T, Manolakis A, Buchalla W, \& Hannig C (2003) Influence of tea on intrinsic colour of previously bleached enamel Journal of Oral Rehabilitation 30(5) 488-494.

31. Mellberg JR (1992) Hard-tissue substrates for evaluation of cariogenic and anti-cariogenic activity in situ Journal of Dental Research 71 (Special Number) 913-919.

32. Bowles WH, \& Ugwuneri Z (1987) Pulp chamber penetration by hydrogen peroxide following vital bleaching procedures Journal of Endodontics 13(8) 375-377.

33. Costa CA, Riehl H, Kina JF, Sacono NT, \& Hebling J (2010) Human pulp responses to in-office tooth bleaching
Oral Surgery, Oral Medicine, Oral Pathology, Oral Radiology, and Endodontics 109(4) e59-64.

34. Hanks CT, Fat JC, Wataha JC, \& Corcoran JF (1993) Cytotoxicity and dentin permeability of carbamide peroxide and hydrogen peroxide vital bleaching materials, in vitro Journal of Dental Research 72(5) 931-938.

35. Lee DH, Lim BS, Lee YK, \& Yang HC (2006) Effects of hydrogen peroxide $\left(\mathrm{H}_{2} \mathrm{O}_{2}\right)$ on alkaline phosphatase activity and matrix mineralization of odontoblast and osteoblast cell lines Cell Biology and Toxicology 22(1) 39-46.

36. Tan L, Chen NN, Poon CY, \& Wong HB (2006) Survival of root filled cracked teeth in a tertiary institution International Endodontic Journal 39(11) 886-889.

37. Ellis SG (2001) Incomplete tooth fracture-proposal for a new definition British Dental Journal 190(8) 424-428.

38. Rivera EM, \& Williamson A (2003) Diagnosis and treatment planning: Cracked tooth Journal of the Tennessee Dental Association 83(2) 38-41.

39. Kruger BF (1984) Cracked cusp syndrome Australian Dental Journal 29(1) 55.

40. Stanley HR (1968) The cracked tooth syndrome Journal of the American Academy of Gold Foil Operators 11(2) 36-47.

41. Ozer SY (2011) Detection of vertical root fractures by using cone beam computed tomography with variable voxel sizes in an in vitro model Journal of Endodontics 37(1) 75-79.

42. Opdam NJ, Roeters JJ, Loomans BA, \& Bronkhorst EM (2008) Seven-year clinical evaluation of painful cracked teeth restored with a direct composite restoration Journal of Endodontics 34(7) 808-811.

43. Opdam NJ, \& Roeters JM (2003) The effectiveness of bonded composite restorations in the treatment of painful, cracked teeth: Six-month clinical evaluation Operative Dentistry 28(4) 327-333.

44. Sauro S, Mannocci F, Toledano M, Osorio R, Thompson I, \& Watson TF (2009) Influence of the hydrostatic pulpal pressure on droplets formation in current etch-and-rinse and self-etch adhesives: A video rate/TSM microscopy and fluid filtration study Dental Materials 25(11) 1392-1402.

45. Sauro S, Pashley DH, Montanari M, Chersoni S, Carvalho RM, Toledano M, Osorio R, Tay FR, \& Prati C (2007) Effect of simulated pulpal pressure on dentin permeability and adhesion of self-etch adhesives Dental Materials 23(6) 705-713.

46. Buzalaf MA, Hannas AR, \& Kato MT (2012) Saliva and dental erosion Journal of Applied Oral Science 20(5) 493-502.

47. Karlinsey RL, Mackey AC, Blanken DD, \& Schwandt CS (2012) Remineralization of eroded enamel lesions by simulated saliva in vitro Open Dentistry Journal 6 170-176. 